\title{
Vowel duration, compression and lengthening in stressed syllables in Central and Southern varieties of standard Italian
}

\author{
John Hajek ${ }^{1}$, Mary Stevens ${ }^{1}$ \\ ${ }^{1}$ School of Languages and Linguistics, University of Melbourne, Melbourne, Australia, \\ johnth@unimelb.edu.au, mes@unimelb.edu.au
}

\begin{abstract}
This study is the first investigation of the effects of regional accent on temporal organization, specifically of vowel duration, in stressed syllables in standard Italian. We examine possible compression effects on the duration of stressed vowels according to word-position (final, penult and antepenult) and syllable type (open vs. closed) in central v. southern varieties of (standard) Italian. Our results show significant regional differences in some contexts, i.e. closed syllables, and antepenultimate position, but not in others. We consider the implications of our results for the phonological description and phonetic investigation of Italian, and the extent to which any such differences may be accounted for. Index Terms: Italian, vowel duration, syllable compression, stress, lengthening, regional variation
\end{abstract}

\section{Introduction}

The principal aim of this study is to examine the possible influence of regional accent on the duration of stressed vowels in a range of inter-related contexts in Italian. It will allow us to determine in what way different regional varieties might interact with the effects, if any, on Italian vowel duration of the following factors: (a) syllable structure (open vs. closed syllables); and (b) relative stress position in the word (final vs. penultimate vs. antepenultimate syllables).

Although these issues relating to temporal structure have been previously investigated for Italian, e.g. $[2,3,5,7,12$, $13]$ and others, an experimental study comparing the possible effects of regional accent type on results does not appear to have been previously undertaken. This omission is somewhat surprising given the extent of regional variation on the pronunciation of standard Italian, even amongst highly normative speakers. With few exceptions, it is usually possible to correctly identify the accent of a native speaker of Italian according to at least supra-regional level (northern, central or southern). More localized identification, down to specific region or city is also often possible, or at least assumed to be so by native listeners. This situation reflects the high degree of linguistic fragmentation that developed historically in Italy after the collapse of the Roman Empire, and which only became to be significantly changed in the late $19^{\text {th }}$ and $20^{\text {th }}$ centuries after political unification of Italy. ItaloRomance dialects, related to one degree or another to what we know as standard Italian (itself a variety of Tuscan, spoken in Central Italy), were until at least the mid- $20^{\text {th }}$ century spoken by almost all Italians, and in some regions continue to be widely used today. Many speakers are now actively monolingual in standard Italian only, but regional and local influence on their spoken accent is normally evident, including on vowel patterning, and prosodic features such as intonation and segment duration (see also below).

\subsection{Previous experimental investigation of Italian temporal structure and vowel duration}

Independent of the effect of regional accent, and despite a number of earlier descriptive and experimental studies, many aspects of the temporal structure, especially of stressed vowels, in Italian, remain uncertain (as described immediately below. See also [5]). This new study also has, therefore, the additional aim of providing experimental data that can be added to the existing body of work - experimental and descriptive, phonetic and phonological - that might be useful in providing a more accurate overview and understanding of Italian temporal structure, especially as it pertains to vowel duration.

The results of earlier studies on Italian vowel duration and temporal structure are notably inconsistent. For instance, there is disagreement as to the extent, if any, of word-level compression effects on stressed vowel duration (see [12] for overview). However more recently, [3, 5] and [12] have confirmed a regular phonetic compression effect as post-tonic syllables are added, at least in a comparison between penultimate and antepenultimate stress ('CVCV and 'CVCVCV). There is, in general, less, and often conflicting, information on compression effects on word-final $\left(\mathrm{CV}^{\prime} \mathrm{CV}\right)$ vowels vs. other positions (cf. [5] and [7]).

Questions also remain about the general applicability of specific findings. There is, for instance, agreement that stressed vowels in closed syllables in Italian are always much shorter in duration than stressed vowels in open syllables. However, judgments of this kind are for the most based on comparisons between open and closed syllables in penultimate position only. Whether stressed vowels in wordfinal or antepenultimate open syllables are also necessarily longer than vowels in closed syllables is unclear. This is an important point since phonological descriptions of Italian (e.g. [14]) consider stressed vowels in final position to be identical in terms of length/duration to vowels in closed syllables i.e. always short both in phonological and phonetic terms. On the other hand, stressed antepenults and penults in open syllables are normally considered to be phonologically and phonetically equivalent (but see also §2), and, therefore much longer than stressed vowels in closed syllables.

Our understanding of the interaction between basic prosodic structure and vowel duration in Italian has also been hampered by substantial methodological differences that do not allow for useful comparisons. Some studies have investigated words in isolation, while others have looked at items in carrier phrases. There is variable use of real vs. nonsense words, and the number of subjects is frequently very limited - sometimes only one speaker. There is also significant variation in the regional origin of subjects, which is otherwise known to impact significantly on the pronunciation of Italian by 'native' speakers. In particular, we note that many studies on vowel duration and compression in Italian, e.g. $[2,13]$, have relied on very small numbers $(1-2)$ 
of speakers drawn from Northern Italy, where the historical development of vowel properties including duration/length is known to be very different from that expected for the traditional normative variety of Italian described above (see also $\S 2$ below). In other cases, e.g. [12], speaker origin is not mentioned. However, in all of these studies, little or nothing has been made of the possible consequence of regional origin on results presented.

\section{Prosodic structure, stressed vowel length and duration in Italian and Italo- Romance dialects}

From a historical perspective, the Italo-Romance dialects spoken throughout Italy are normally divided into two major groupings: (1) Northern; and (2) Centro-Southern. The former is native to all regions north of the Apennine mountains, including Emilia-Romagna (e.g. Bologna), Lombardy, and Piedmont. Centro-Southern Italian dialects, spoken south of the Apennines, are further divided into Central and Southern varieties. Although much more closely related to each other than to Northern dialects, they also show considerable divergence across a wide range of areas, and mutual intelligibility is often very difficult or impossible. Standard Italian is based on Tuscan, a Central variety spoken in Central Italy, which also includes Lazio (e.g. Rome) and the Marches. Southern Italo-Romance extends from southern Lazio all the way down to Sicily, and includes Abruzzo, Campania, Lucania, Calabria and Puglia. Centro-Southern Italo-Romance differs significantly from Northern Italo-Romance, in terms of segmental and prosodic structures and processes.

In the North, amongst other things, there is a tendency towards lengthening of word-final stressed vowels; regular loss of word-medial long consonants matched by the development of contrastive vowel length, e.g. /'pappa/ > /'papa/ 'mush' and /'papa/ > /pa:pa/ 'pope' respectively; and the complete absence of sandhi gemination at wordboundaries, e.g. /'pju 'latte/ ['pju 'latte] 'more milk' instead of normative ['pju l'latte] (otherwise known as raddoppiamento sintattico and typical of Centro-Southern Italian [1, 6, 8, 14]). Speakers of Northern varieties often transfer these patterns into their pronunciation of standard Italian. However, phonological accounts, and normative descriptions of standard Italian always describe it without these Northern features. For this reason, we exclude standard Italian as spoken by Northern Italian speakers from further consideration in this study.

With respect to Central and Southern Italo-Romance, it is traditionally assumed they share the same basic prosodic and temporal structures, e.g. $[1,3,6]$, and the possibility that the interaction between temporal structure and vowel duration may be different in each has not been considered - especially from an experimental phonetic perspective.

In phonological terms, Italian (and other varieties of Centro-Southern Italo-Romance) is traditionally characterised as having an entirely predictable distribution of vowel length in stressed position: vowels are always long in word-medial open syllables, e.g. /'papa/ ['pa:pa] 'pope', /'papero/ ['pa:pero] 'gander', but are always short in closed syllables, e.g. /'pappa/ ['pappa] 'mush', and in word-final final position, e.g. /pa'pa/ [pa'pa] 'dad' (see, e.g. [6, 7, 8, 14] for details). The presence of unstressed syllables to the left or the right of the stressed syllables is not usually considered to have an effect on the phonological length of stressed vowels.

However, in many varieties of Centro-Southern Italian, and in particular across much of Southern Italy, there is regular phonetic shortening of the antepenultimate vowel triggering secondary gemination of the following consonant, e.g. /'kammera/ ['kammera] instead of expected /'kamera/ ['ka:mera] 'room', as speakers apparently try to maintain even syllable weight (either 'CV: or 'CVC) across word-medial stressed positions. Occasional lexicalized examples of the same phenomenon are found in standard Italian (inherited from Tuscan), e.g. /'attimo/ ['attimo] instead of expected /'atimo/ ['a:timo] 'moment' [8]. But all of these facts are overlooked in synchronic treatments of vowel length distribution in standard Italian.

In word-final position, the traditional view (e.g. [3, 6, 8, 14]) is that stressed vowels are short, both phonologically and phonetically, in isolation or before another word, across Central and Southern Italy. If this is true, then Italian (and Centro-Southern Italo-Romance) is typologically unusual in this respect because across languages word-final stressed vowels have predictably longer duration [11, 13]. This shortening runs counter to the word-level compression hypothesis that stressed vowel duration will be greatest in word-final position and will be compressed through the addition of a post-tonic unstressed syllable, i.e. all other things being equal, the stressed vowel in /'papa/ $(+1$ post-tonic syllable) will be shorter in duration than final /a/ in /pa'pa/. However, not all sources (in particular [1, 10]) on Italian agree on short final vowels, claiming instead that final stressed vowels need not surface as short, as they are subject to optional lengthening, i.e. /pa'pa/ [pa'pa] [pa'pa:] in Italian spoken in Centro-Southern Italy.

These conflicting facts and trends point to three different hypotheses with respect to possible interaction between regional variety or accent on the one hand, and vowel duration and syllable-level and word-level compression on the other in our sample of Italian: (1) there will be no significant difference between Central and Southern accents with respect to the impact of closed vs. open syllable structure on stressed vowel duration, since this is not disputed by anyone; (2) the duration of open stressed vowels in antepenultimate syllables may be shorter in Southern accents of Italian, given the historical pattern of regular vowel shortening (also triggering secondary gemination) considered to be more typical of Southern rather than of Central varieties of Italo-Romance; (3) there will be no regional difference in stressed final vowel duration. If final stressed vowels are always short in Central and Southern Italy, as many sources insist, there will be no right-to-left compression effect - indeed, vowel duration should be significantly shorter in final position in both varieties. Alternatively, we might find, for both Central and Southern speakers, optional final lengthening which will serve to cancel out any final shortening effect.

The results of this study will be useful in (dis)proving these hypotheses by testing specifically for possible regional differences (central vs. southern) not previously considered, as well as for any regionally conditioned interactions between basic prosodic structures and vowel duration in Italian.

\section{Methodology}

We recorded eight native speakers of Italian divided equally according to regional origin and linguistic affiliation, i.e. Central and Southern Italy respectively. Each group consisted of 2 male and 2 female subjects, between the ages of 24 and 40 , all middle-class university graduates born and educated in Italy. While all subjects speak a normative or very close to normative variety of Italian, the general regional origin of each individual, as a speaker of either a Central or Southern variety of Italian, could still be identified on listening by their 
spoken accent, primarily through differences in intonation and minor phonetic isoglosses, e.g. the distribution of open and closed mid vowels and the intervocalic (non-)voicing of $/ \mathrm{s} /$.

Six real words were selected for recording. In each case the stressed vowel was /a/. Minimal pairs were chosen that would allow for direct comparison of: (a) open vs. closed syllable (/'papa/ 'pope' vs. /'pappa/ 'mush'); and (b) different stressed syllable positions (/papero/ 'gander' vs. /pa'pato/ 'papacy' and /'papa/ 'pope', vs. /pa'pa/ 'dad'.

Subjects were asked to insert test items into the carrier phrase Dico lentamente 'I say slowly' which was repeated four times for each item. We then measured, using Praat, the duration of stressed vowels across all contexts under examination. There were 32 tokens for each item in each recorded context. After results were averaged for each speaker and across speakers, we conducted initial statistical analysis (t-tests) of results for the entire group as well as for each regional sub-group, with, at this stage, only limited statistical treatment of individual speakers.

\section{Results}

\subsection{The effect of syllable structure}

We first examine stressed vowel duration in open and closed syllables in penultimate position. This comparison is uncontroversial - for all speakers we expect to find a clear (syllable-conditioned) difference in long vs. short vowel duration. As such, it would also provide a useful baseline for long and short vowel duration in all other conditions.

Table 1: Stressed vowel duration before short and long $/ \mathrm{p}$ $\mathrm{pp} /$ respectively (std deviations in brackets)

\begin{tabular}{|c|c|c|c|}
\hline & overall & central & southern \\
\hline pàpa & $180(25)$ & $183(32)$ & $177(22)$ \\
pàppa & $124(21)$ & $135(25)$ & $112(2)$ \\
\hline
\end{tabular}

Not surprisingly, our results show highly significant vowel shortening in closed syllables $(p<0.005)$ - with the same pattern consistent across regional variety and all speakers.

There was no effect of regional variety on the duration of the stressed vowel in the open penult $(p=0.26)$. However, the difference $(23 \mathrm{~ms}$.) in the duration of the stressed vowel in the closed penult was significant $(p=0.009)$, with all southern speakers producing shorter vowels, always below the overall average and with minimal variability. While consonant duration is not a particular focus of this study, the geminate /pp/ (overall $228 \mathrm{~ms}$.) was always significantly longer, as expected, than singleton $/ \mathrm{p} /$ (overall $111 \mathrm{~ms}$.) for all eight speakers individually and combined $(\mathrm{p}<0.005)$. The extent of this duration difference is consistent with earlier findings, e.g. [5], and reflects the robustness and fully phonemic nature of the long vs. short consonant distinction in Italian.

\subsection{The effect of penultimate vs. final position}

With respect to stressed vowels in penultimate and final position, Table 2 shows they did not differ significantly in duration at either national or regional levels $(\mathrm{p}>0.1)$.

Table 2: Stressed vowel duration in penultimate (pàpa) and final (papà) open syllables (std deviations in brackets).

\begin{tabular}{|c|c|c|c|}
\hline Ss & overall & central & southern \\
\hline pàpa & $180(25)$ & $183(32)$ & $177(22)$ \\
papà & $174(15)$ & $174(8)$ & $175(21)$ \\
\hline
\end{tabular}

These results (whereby stressed vowels in word-final and penultimate open syllables are both long in terms of duration) confirm recent findings by [5] but do not appear to be consistent with traditional phonological and other sources (cf. $\S 2)$ in which word-final stressed vowels are always described as short in Italian. We return to this important point in $\S 5$.

However, we also note substantial inter- and intraspeaker variation in the case of stressed /a/ in final open position. In each regional set of 4 subjects, two speakers had longer final vowels than penults, while penults were longer than final vowels for the other two subjects. At the same time, very high standard deviations in word-final position (up to $79 \mathrm{~ms}$.) also point to an optional process of lengthening/shortening for speakers in that context.

\subsection{The effect of antepenultimate vs. other positions}

In Table 3, we provide duration results for stressed vowels in trisyllabic words that differed in stress placement (antepenult vs. penult vs. final).

Table 3: Stressed vowel duration in open syllables according to word position (std dev.ns in brackets).

\begin{tabular}{|c|c|c|c|}
\hline & overall & central & southern \\
\hline pàpero & $154(31)$ & $168(24)$ & $140(33)$ \\
papàto & $192(28)$ & $194(33)$ & $190(28)$ \\
papà & $174(15)$ & $174(8)$ & $175(21)$ \\
\hline
\end{tabular}

Overall and at regional level, vowels were always significantly shorter in antepenult position than in penult position $(\mathrm{p}<0.0001)$. Shortening in the same direction was found for all speakers, although the effect is noticeably greater for southern speakers (av. $50 \mathrm{~ms}$.) than for central speakers (av. $26 \mathrm{~ms}$.). The duration difference between trisyllabic /'papero/ and disyllabic/'papa/ (see Table 2) was also significant - both overall and for each regional variety. However, the effect, very strong overall and for Southern Italian, was slightly weaker for central Italian $(p=0.019)$.

The difference in duration between antepenultimate $/ \mathrm{a} /$ in /'papero/ and final /a/ in /pa'pa/ was only significant overall (p $=0.01$ ) but not at regional level. This result appears to reflect the greater variability in the duration of final stressed vowels seen in results for individual speakers but not evident in averaged standard deviations in Table 3 . Not surprisingly, the stressed vowel in /'papero/ is significantly longer than short /a/ in /'pappa/ (Table 1) both overall and at regional level (always $\mathrm{p}<0.001$ ). However, we note that for at least one Southern subject (GR), antepenultimate duration was noticeably shorter (at $98 \mathrm{~ms}$.), and equivalent to or even below vowel duration in (short) closed syllable position in /'pappa/ (111 ms.). For all other speakers, antepenults were always longer, the difference ranging from 21 to $60 \mathrm{~ms}$.

\section{Discussion and conclusions}

Our results show that while there are many shared patterns in contexts we tested, Central and Southern accents do differ with respect to vowel duration effects in standard Italian in some areas, with at least one unexpected finding.

In the first instance, syllable structure has a fully predictable impact on stressed vowel duration - both overall, and across regional variety: vowels are much shorter in closed than in open syllables. Unexpected, however, was the significantly and consistently shorter duration $(-23 \mathrm{~ms}$.) of the short vowel in closed syllable position in the Southern variety 
when compared to the Central variety. The reason for this finding remains unknown.

With respect to possible right-to-left compression effects, some caution is needed given the complexities and competing hypotheses we pointed to in $\$ 2$ regarding final vowel duration in Italian. At this stage, however, we can give partial confirmation of earlier findings of word-level compression (e.g. [5], [12]): the addition of a post-tonic unstressed syllable has a significant effect on stressed vowel duration in Italian both overall and across regional variety - but only in the case of antepenultimate ( +2 post-tonic syllables) vs. penultimate stressed vowel $(+1$ post-tonic syllable) positions. There is, however, no strictly linear effect (i.e. $0,+1,+2$ syllables). Moreover, the shortening effect in antepenults is found to be much stronger in Southern variety (up to $50 \mathrm{~ms}$.) than in the Central variety, as was predicted by our second hypothesis, and supported by historical developments found to be more common in Southern Italo-Romance. Indeed, as already noted, for at least one Southern speaker (GR), antepenultimate shortening is particularly marked - with duration values equivalent to that found in short closed syllable position. In phonological terms, the overall phonetic pattern of antepenultimate shortening also supports the proposal in [4] that stressed vowels are no more than half-long in antepenultimate open syllables - in both Central and Southern varieties of Italian tested here.

Matters are more complicated, however, with regard to word-final duration: there is no difference - whether overall or at regional level - between /'papa/ /'papato/ $(+1$ post-tonic syllable) and /pa'pa/ (no post-tonic syllable), with consistently similar duration figures across regions. In $\$ 2$ two possible scenarios were outlined with regard to relative duration of final and penult vowels: (a) final $>>$ penult; or (b) final $=$ penult. Our results provide greatest support for scenario (b) the absence of an overall duration effect in any direction is explained by optional lengthening/shortening in final position. As noted in our discussion at $\$ 4.2$, there is considerable variation across and within speakers: in each regional set two speakers lengthen final vowels relative to penults, while for two subjects the trend relationship is reversed. Moreover, high levels of intra-speaker variability are also evident in the same context, providing additional support for optional final lengthening/shortening (similar experimental results were previously reported by [5] for 6 Centro-Southern speakers not controlled for regional accent). This finding raises the question of whether phonological accounts of Italian should treat word-final stressed vowels as phonologically long, and optionally shortened, or vice versa. The optionality of this process, in particular, is not in line with traditional accounts, which, as noted in $\S 2$, propose that word-final stressed vowels always surface as short in all circumstances. We suggest that any new descriptions of standard Italian should now accept optional final lengthening as inherently characteristic, as already proposed by [1], and [10] and already confirmed experimentally by [5].

Competing tendencies in final position ensure word-level compression by post-tonic syllable addition is not strictly linear and cumulative in either regional variety of Italian: our data show it is only clearly evident when 2 post-tonic syllables are attached. Further work is needed to understand why this restricted pattern might be the case. At this stage it is possible that (optional) final glottalization, (see $[9,10,11]$ ), may account for this discrepancy, but requires further investigation.

Our results show that at least in some contexts the different regional accents of Central and Southern Italy can have a significant effect on the interaction between basic prosodic structures and vowel duration in Italian, in ways not previously tested nor clearly understood. The normative variety of standard Italian is historically a variety of Central Italo-Romance, and remains such. Phonetic features that are exclusively associated with either Northern or Southern Italy only are not accepted in traditional and prescriptive descriptions of standard Italian, and need to be controlled for. Researchers investigating prosodic structures and vowel duration in standard Italian need, therefore, to be aware of the possible influence of different regional origin - since even those regional accents associated with varieties of ItaloRomance considered to be historically very close, i.e. Central and Southern Italian, can still show significantly different effects. At this stage, much more research is also required to understand the basis of some of the regional (Central vs. Southern) effects we have observed. Future attention should also be given to possible regional effects on the pronunciation of standard Italian involving possible compensatory interaction between stressed vowels and post-tonic consonants, given widespread antepenultimate shortening and post-tonic gemination often found in Southern Italian dialects, e.g. /'kammera/ 'room' alongside historical /'kamera/ still found in standard Italian and Central Italy.

\section{References}

[1] Absalom, M., Hajek, J. 1997. Raddoppimaneto sintattico: what happens when the theory is on too tight? In Bertinetto, P. M., Gaeta, L., Jetchev, G. \& Michaels, D. (eds.) Certamen Phonologicum III. Turin: Rosenberg \& Sellier, 159-179.

[2] Bertinetto, P.M. 1981. Strutture prosodiche dell'Italiano. Florence: Accademia della Crusca.

[3] D'Imperio, M. Rosenthall, S. 1999. Phonetics and phonology of main stress in Italian. Phonology 16: 1-28.

[4] Hajek, J. 2000. How many moras? Overlength and maximal moraicity in Italy. In Repetti, L. (ed) Phonological theory and the dialects of Italy. Amsterdam: John Benjamins. 111-135.

[5] Hajek, J., M. Stevens, G. Webster. 2007. Vowel duration, compression and lengthening in stressed syllables in Italian. ICPhS XVI Saarbrücken:1057-1060.

[6] Maiden, M. 1995. A linguistic history of Italy. London: Longman.

[7] Marotta, G. 1985. Modelli e misure ritmiche: la durata vocalica in italiano. Bologna: Zanichelli.

[8] Rohlfs, G. 1966. Grammatica storica della lingua italiana e dei suoi dialetti. Vol. 1 Fonetica.

[9] Stevens, M., Hajek, J., Absalom, M. 2002. Raddopppiamento sintattico and glottalization phenomena in Italian: a first phonetic excursus. Proc. SST 9 Melbourne: 154-159.

[10] Stevens, M., Hajek, J. 2006. Blocking of word-boundary consonant lengthening in Sienese Italian: some auditory and acoustic evidence. Proc. SST 11 Auckland: 176-181.

[11] Vayra, M. 1994. Phonetic explanations in phonology: laryngealization as the case for glottal stops in Italian word-final stressed syllables. In Dressler, W. U., Prinzhorn, M. \& Rennison, J. R. (eds) Phonologica 1992: Proc. $7^{\text {th }}$ International Phonology Meeting. Turin: Rosenberg \& Sellier.

[12] Vayra, M., Avesani, C., Fowler, C. A. 1999. On the phonetic basis of vowel-consonant coordination in Italian: a study of stress and "compensatory shortening". Proc. $14^{\text {th }}$ ICPhS San Francisco: 495-498.

[13] Vayra, M., Fowler, C. A., Avesani, C. 1987. Word-level coarticulation and shortening in Italian and English speech. Studi di grammatica italiana 13: 249-269.

[14] Vogel, I. 1982. La sillaba come unità fonologica. Bologna: Zanichelli 